\title{
A Planar Fractal Micro-Transformer with Air Core and Hilbert Curve
}

\author{
Yong Zhu $\cdot$ Fahimullah Khan $\cdot$ Junwei Lu $\cdot$ Dzung Viet Dao
}

\begin{abstract}
In this paper, a novel MEMS-based planar fractal transformer is presented. Space-filling property of Hilbert curve is exploited for the miniaturization of integrated transformers. Compared to traditional spiral transformer, the fractal Hilbert transformer requires only one metal layer and no interconnection vias or crossovers, thereby reducing micro-fabrication complexity, EMI interference and resistive loss in the cross-overs. The transformer is implemented in a low-cost MetalMUMPs standard process. The transformer is coreless and the silicon underneath the primary and secondary coils is removed to mitigate the parasitic capacitance. The dc resistance of the transformer is 0.78 $\Omega$, and the primary inductance of $9.3 \mathrm{nH}$ has been obtained at $30 \mathrm{MHz}$. The quality factor of the transformer at $60 \mathrm{MHz}$ is 1.6 and the total area of the transformer is $0.27 \mathrm{~mm}^{2}$. The obtained inductance density of $35 \mathrm{nH} / \mathrm{mm}^{2}$ is better than other air core transformers thus far in the literature.
\end{abstract}

\section{Introduction}

With the growing demand for portable electronic devices, the desire for monolithic power converters is rapidly increasing day by day. Power supplies with isolated dc-dc converters require monolithic transformers with high efficiency. Transformers with magnetic core exhibit relatively high loss and compromised isolation at high frequencies due to degradation in magnetic core performances with the increase of frequency. Several ferrite core magnetic transformers have been reported in (Huang et al., 1995, Mino et al., 1996, Wang et al., 2008). However, efficiency, operating frequency, and current limitation are the main challenges because of the magnetic saturation and eddy current losses in the ferrite magnetic core material at high frequencies. However, it is observed that the performance of the air core transformer is better than the magnetic core counterpart at high frequencies due to no lossy core material involved in air core transformers. A transformer (Mino et al., 1996) with an inductance density of $40 \mathrm{nH} / \mathrm{mm}^{2}$ at $10 \mathrm{MHz}$ suffered a decrease in inductance density at $30 \mathrm{MHz}$ due to a decrease in permeability of the core material. Moreover, the transformer's magnetic core also gets saturated at high currents as reported in (Meere et al., 2011).

Several on-chip micro-transformers have been fabricated on high resistive substrate or low-K dielectric films (Arshak and AlMukhtar, 1999; Wu et al., 2000; Yunas et al., 2009). The aim was to reduce the eddy currents in the substrate for a higher quality factor of the transformer. To reduce the parasitic effects, many transformers have been fabricated with trenched silicon substrate and suspended spiral structures on the top (Ribas et al., 2000), and out of plane structures (Jiang et al., 2000). A quality factor of less than 1 is reported at 20 $\mathrm{MHz}$ for the dc-dc converter (Wang et al., 2008). However, the complex fabrication process and high costs are the major hindrances in the development of on-chip power converters.

In this paper a novel MEMS-based fractal transformer with air core and Hilbert curve is presented. The transformer is coreless to eliminate the eddy current loss in the ferrite magnetic core material. The silicon underneath the primary and secondary coils is removed to mitigate the parasitic capacitances. The primary and secondary windings are implemented in a planar fractal geometry of Hilbert curve. The space-filling property of Hilbert fractal curve is exploited to cover the maximum designated area with transformer turns. In addition, the fractal transformers are less complex and low-cost compared to traditional planar spiral transformers. For instance, to lead out inner ports inside the coil, the spiral transformer requires two metal layers and interconnection 
vias or cross-overs, which can induce EMI interference and high contact resistance. The fractal transformers require only one metal layer and no interconnection vias or cross-overs, thereby eliminating the issues mentioned above in traditional spiral transformers. This research helps to advance the power supply on chip (PwrSoC) for monolithic integration of MEMS sensors, actuators, and ICs.

\section{Fractal Hilbert Curve}

Fractal is a mathematical abstract. It is self-similar and its dimension is a fraction between 1 and 2. One of the most appealing examples of fractal geometry is the Hilbert curve. With a fractal dimension of $\mathrm{D}=2$, the curve ideally features an infinite length and fills up every corner in a bounded squared surface. Fig. 1 illustrates the first 3 iterations of the Hilbert curve. The curve growths exponentially at each iteration and completely fills up a squared surface. There is not a better way to package the same length in a smaller area. This space-filling property has been used in nature for millions of years to optimize the energy transportation, for example, coastlines, leaf shapes, and Brownian moment path, etc. (Fractus, 2001;

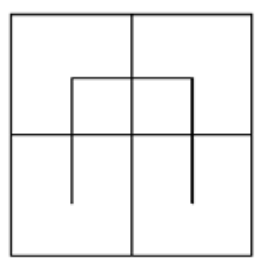

(a)

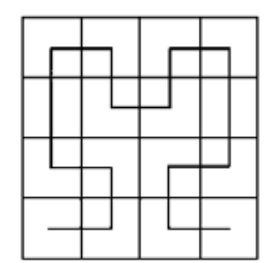

(b)

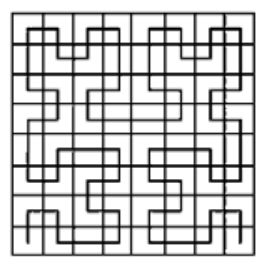

(c)
Stojanovic et al. 2008; Wang et al. 2012).

Fig. 1 Hilbert cures: (a) iteration 1; (b) iteration 2; (c) iteration 3.

\section{Transformer Design and Fabrication}

The space-filling property of Hilbert curve has been exploited to miniaturize the space occupied by the transformers using two metal layers (Stojanovic et al. 2008; Panchal et al. 2011). To reduce the microfabrication complexity, cost, and cross-over losses, a novel Hilbert micro-transformer using a single metal layer is proposed and implemented in this paper. As depicted in Fig. 2, the pattern of the primary and secondary coils is

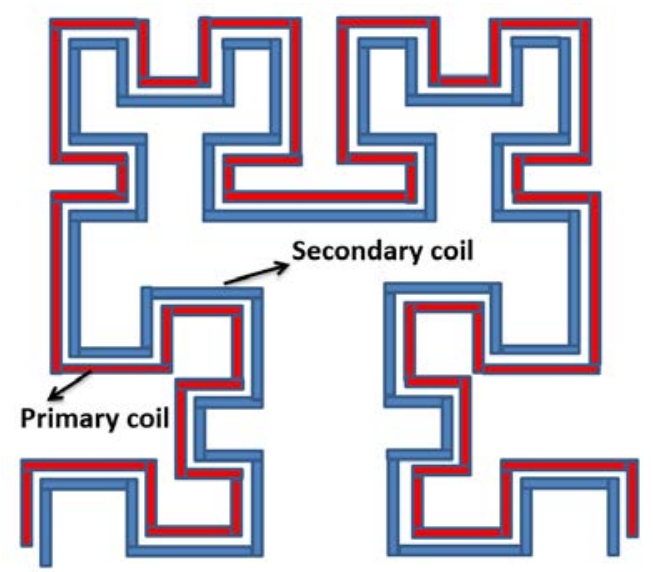

the $3^{\text {rd }}$ iteration of Hilbert curve and the turning ratio is $1: 1$. Both primary and secondary coils are planar with the same metal layer. Compared to traditional planar spiral transformers, there are no vias or through-holes for interconnections, thereby reducing micro-fabrication complexity, EMI interference and resistive loss in the cross-overs.

Fig. 2 Schematic diagram of the fractal Hilbert transformer (iteration 3).

There are some trade-offs in designing the microtransformer and the selection of transformer parameters. For example, the parasitic capacitance depends upon the transformer's lateral and vertical dimensions, whereas the self-inductance of the primary and secondary coils of the transformer depends upon the lateral dimensions. Table 1 shows the optimized design parameters of the Hilbert transformer.

\begin{tabular}{cc}
\hline \hline Design Parameters & Values \\
\hline Frequency Range $(\mathrm{MHz})$ & $1-100$ \\
Area $\left(\mathrm{mm}^{2}\right)$ & 0.27 \\
Winding Ratio & $1: 1$ \\
Winding Gap $(\mu \mathrm{m})$ & 10 \\
Winding Width $(\mu \mathrm{m})$ & 10 \\
Winding Thickness $(\mu \mathrm{m})$ & 20.5 \\
Air Trench $(\mu \mathrm{m})$ & 25 \\
Inductance $(\mathrm{nH})$ & $6-10$ \\
Core material & $\mathrm{Air}$ \\
Coil material & $\mathrm{Ni}+\mathrm{Au}$ \\
\hline
\end{tabular}

Table 1 Optimized Parameters of the Hilbert Transformer 
The transformer is micro-fabricated in the low-cost MetalMUMPs standard process. As illustrated in Fig. 3, the primary and secondary coils are made of a $20 \mu \mathrm{m}$ thick nickel layer (permeability $=12$ ), and a $25 \mu \mathrm{m}$ trench is etched beneath the coils for suspending the coils in the air. The trench beneath the coils substantially decreases the parasitic capacitance between the coils and the

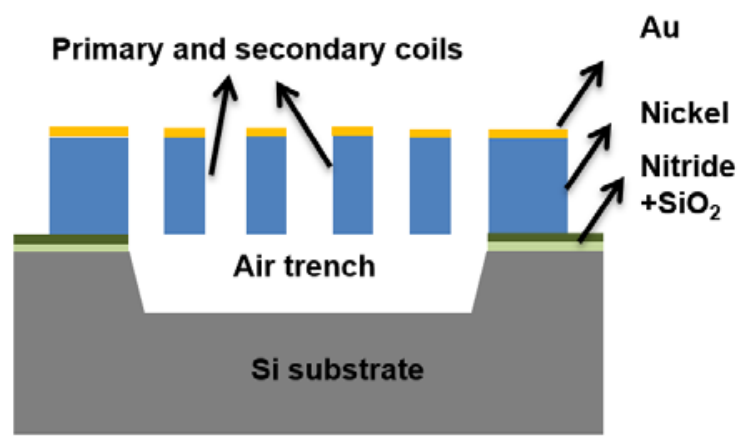

substrate. Furthermore, the trench also diminishes the eddy current in the substrate which helps in improving the quality factor. To avoid high resistance in the transformer it is necessary to increase the thickness of the coil. Therefore, two metal materials of nickel $(20 \mu \mathrm{m})$ and gold $(0.5 \mu \mathrm{m})$ are stacked together to increase the thickness. This technique given in (Soyuer et al., 1995) is used to solve the dc resistance problem of transformers. The SEM image of the fabricated transformer is shown in Fig. 4.

Fig. 3 Cross-sectional view of the fractal Hilbert transformer structure in MetalMUMPs process.

Fig. 4 SEM image of the fractal Hilbert transformer.

\section{Results and Discussions}

The micro-transformer was tested using Cascade Microtech probe station. Dc resistance of $0.78 \Omega$ in both primary and secondary coils was obtained by using fourprobe resistance measurement method. The transformer

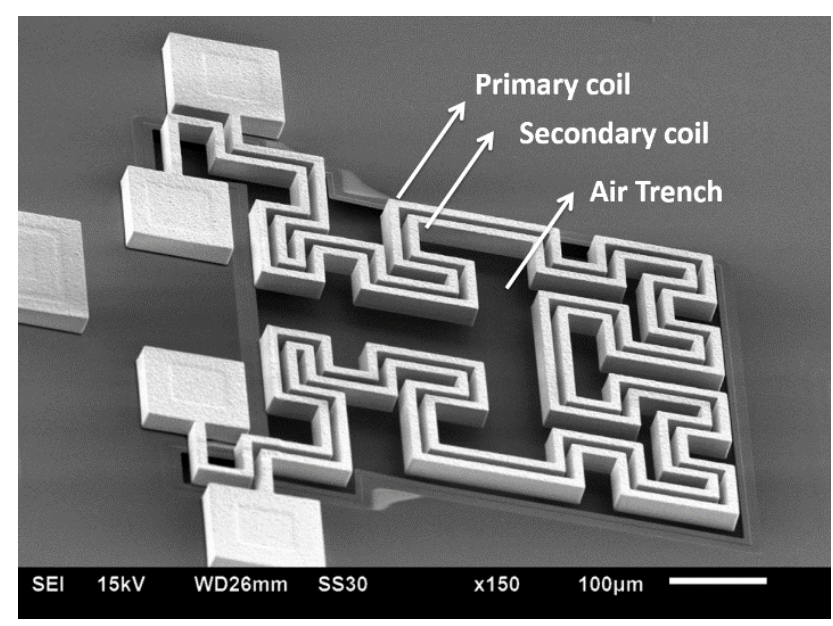

inductances and quality factor were measured from the Zparameters extracted from S-parameters by R\&S ZVL series network analyser, covering the frequency range from $9 \mathrm{kHz}$ to $6 \mathrm{GHz}$. The parasitic inductances and capacitances of coaxial cables and substrate were calibrated and removed by the de-embedding option of the VNA. Single-port measurement was carried out to obtain the open circuit parameters. As the transformer's turn ratio is $1: 1$, the primary inductance is same as the secondary inductance.

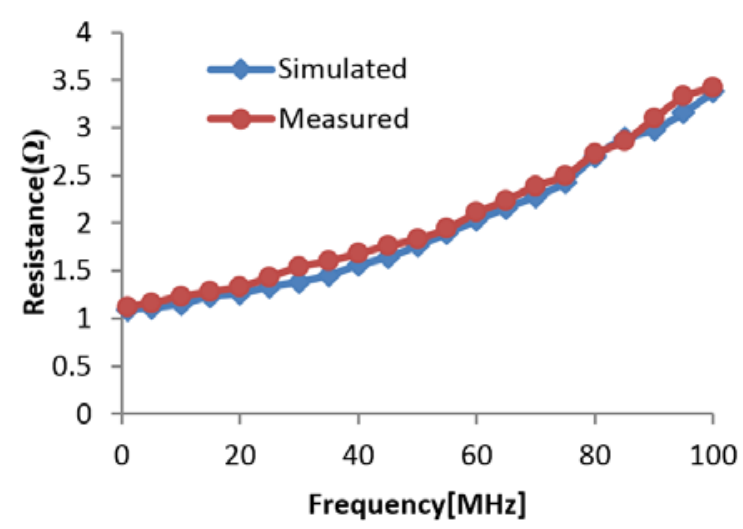

Fig. 5 Comparison of simulated and measured inductances of the fractal Hilbert transformer.

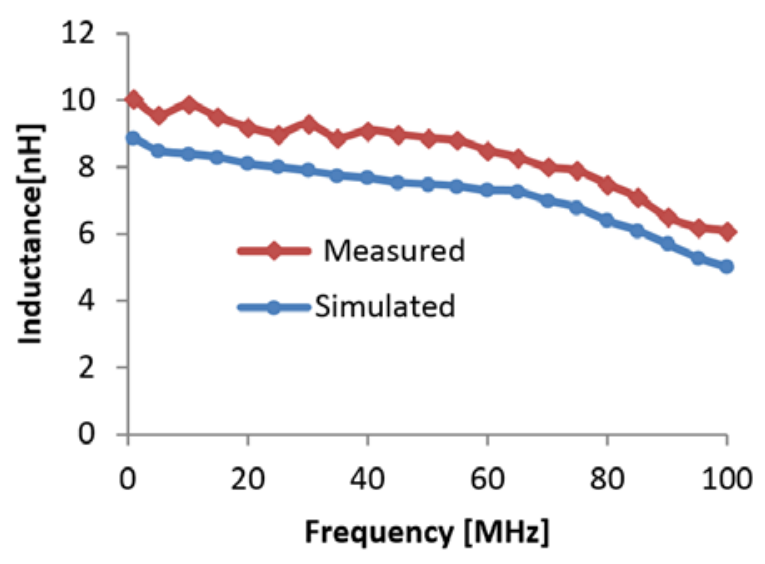

Fig. 6 Comparison of simulated and measured resistances of the fractal Hilbert transformer.

The Hilbert transformer is simulated and optimized in COMSOL multi-physics finite element based software. The simulated and experimentally measured resistances of the primary coil are shown in Fig. 5, illustrating a close match between the design and measurement. Ac resistance at $30 \mathrm{MHz}$ is $1.5 \Omega$ and increases with the increase of frequency due to the skin and proximity effects in the coils. The simulated and experimentally 
measured primary inductances are shown in Fig. 6. It is noted that the primary inductance is approximately $9.3 \mathrm{nH}$ at $30 \mathrm{MHz}$ and decreases with the increase of frequency. The decrease in inductance is due to the increase of parasitic capacitance at high frequencies. Fig. 7 shows the quality factor of the transformer from $1 \mathrm{MHz}$ to 100 $\mathrm{MHz}$. The maximum quality factor is observed as 1.6 at $60 \mathrm{MHz}$ and the decrease of the quality factor is due to the increase of ac resistance at high frequencies.

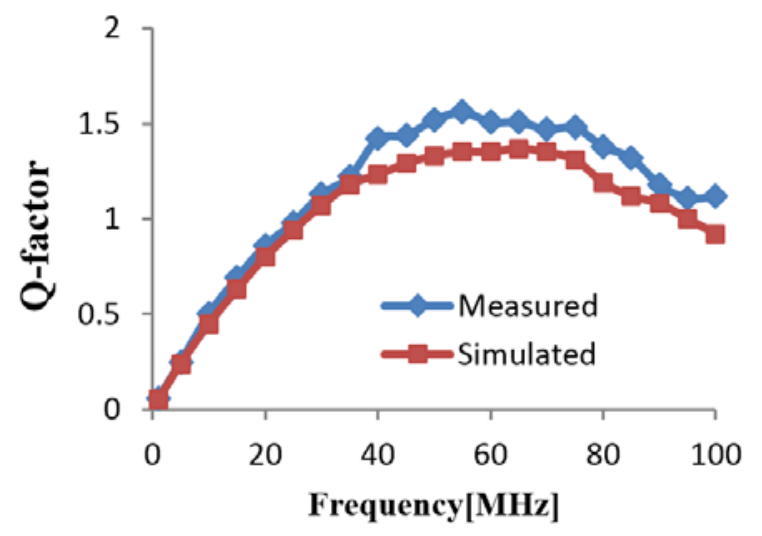

Fig. 7 Comparison of simulated and measured quality factor of the fractal Hilbert transformer.

The measured voltage coupling factor $k$ of the microtransformer is 0.75 at $30 \mathrm{MHz}$. The power efficiency of the transformer at $30 \mathrm{MHz}$ with $50 \Omega$ load is $60 \%$. Thanks to the space-filling property of Hilbert curve, a high inductance density of $35 \mathrm{nH} / \mathrm{mm}^{2}$ is obtained. The results of several different works in the literature have been compared with the results of our findings shown in Table 2. It is observed that the inductance density of this work is higher than other air core transformers or inductors except for some high permeability high resistivity core transformers.

Table 2

Comparison of measured inductance density in the literature

\begin{tabular}{cccc}
\hline \hline Author & $\begin{array}{c}\text { Freq. } \\
(\mathrm{MHz})\end{array}$ & $\begin{array}{c}\text { Core } \\
\text { material }\end{array}$ & $\begin{array}{c}\text { Inductance } \\
\text { density }\left(\mathrm{nH} / \mathrm{mm}^{2}\right)\end{array}$ \\
\hline This study & 30 & Air & 35 \\
R. Wu (2011) & 50 & Air & 18 \\
H.Bergveld,(2008) & 50 & Air & 9.4 \\
Nakazawa (2000) & 3 & Magnetic & 60 \\
N.Wang (2007) & 10 & Magnetic & 14.7 \\
M.Mino (1996) & 30 & Magnetic & 40 \\
\hline
\end{tabular}

\section{Conclusions}

A MEMS-based fractal transformer has been designed, micro-fabricated, and characterized. The obtained high inductance density of $35 \mathrm{nH} / \mathrm{mm}^{2}$ makes it a suitable candidate for power converters in portable devices. The primary inductance of $9.3 \mathrm{nH}$ has been achieved with a quality factor of 1.6 at $60 \mathrm{Mhz}$. Compared to the traditional spiral transformers, only one metal layer is required in the Hilbert transformer, thereby reducing micro-fabrication complexity, EMI interference and resistive loss. The design is fabricated in the standard low-cost MetalMUMPs process. The transformer can be used in on-chip power supply integrated with MEMSbased sensors and/or actuators for the application of efficient power delivery.

\section{References}

ARSHAK, K. \& ALMUKHTAR, B. 1999. Development of high frequency coreless transformer using thick film polymer technology. Microelectronics Journal, 30, 119-125.

BERGVELD, H., KARADI, R. \& NOWAK, K. An inductive down converter system-in-package for integrated power management in battery-powered applications. Power Electronics Specialists Conference, 2008. PESC 2008. IEEE, 2008. IEEE, 3335-3341.

FRACTUS, Fractal Miniaturization in RF and Microwave Networks, www.fractus.com. 2001.

HUANG, X., NGO, K. \& BLOOM, G. Design techniques for planar windings with low resistances. Applied Power Electronics Conference and Exposition. , 1995. IEEE, 533-539.

JIANG, H., WANG, Y., YEH, J.-L. \& TIEN, N. C. 2000. Onchip spiral inductors suspended over deep copperlined cavities. Microwave Theory and Techniques, IEEE., 48, 2415-2423.

MEERE, R., WANG, N., O'DONNELL, T., KULKARNI, S., ROY, S. \& O'MATHUNA, S. C. 2011. Magnetic-core and air-core inductors on silicon: A performance comparison up to $100 \mathrm{MHz}$. Magnetics, IEEE Transactions., 47, 4429-4432.

MINO, M., YACHI, T., TAGO, A., YANAGISAWA, K. \& SAKAKIBARA, K. 1996. Planar microtransformer with monolithically-integrated rectifier diodes for micro-switching converters. Magnetics, IEEE Transactions, 32, 291-296.

NAKAZAWA, H., EDO, M., KATAYAMA, Y., GEKINOZU, M., SUGAHARA, S., HAYASHI, Z., KUROKI, K., YONEZAWA, E. \& MATSUZAKI, K. 2000. MicroDC/DC converter that integrates planar inductor on power IC. Magnetics, IEEE., 36, 3518-3520.

PANCHAL, C., LU, J.W., (2011) High Frequency Planar Transformer (HFPT) for Universal Contact-Less Battery Charging Platform. IEEE Tran. on Magnetics, vol.47, pp.2764-2767. 
PEITGEN, H.-O., JÜRGENS, H. \& SAUPE, D. 2004. Chaos and Fractals: New Frontiers of Science, Springer.

RIBAS, R. P., LESCOT, J., LECLERCQ, J.-L., KARAM, J. M. \& NDAGIJIMANA, F. 2000. Micromachined microwave planar spiral inductors and transformers. Microwave Theory and Techniques, IEEE., 48, 13261335.

STOJANOVIC, G., RADOVANOVIC, M., \& RADONIC, V. (2008) A New Fractal-Based Design of Stacked Integrated Transformers. Active and Passive Electronic Components, vol 2008

SOYUER, M., BURGHARTZ, J., JENKINS, K., PONNAPALLI, S., EWEN, J. \& PENCE, W. 1995. Multilevel monolithic inductors in silicon technology. Electronics letters, 31, 359-360.

WANG, G., XU, L., \& WANG, T. (2012) A Novel MEMS Fractal Inductor Based on Hilbert Curve. Fourth International Conferece on Computational Intelligence and Communication Networks. pp.241244

WANG, N., O'DONNELL, T., MEERE, R., RHEN, F. M., ROY, S. \& O'MATHUNA, S. C. 2008. Thin-filmintegrated power inductor on $\mathrm{Si}$ and its performance in an $8-\mathrm{MHz}$ buck converter. Magnetics, IEEE Transactions, 44, 4096-4099.

WANG, N., O'DONNELL, T., ROY, S., KULKARNI, S., MCCLOSKEY, P. \& O'MATHUNA, C. 2007. Thin film microtransformer integrated on silicon for signal isolation. Magnetics, IEEE., 43, 2719-2721.

WU, R., SIN, J. K. \& HUI, S. 2011. Novel Silicon-Embedded Coreless Transformer for On-Chip Isolated Signal Transfer. Magnetics Letters, IEEE, 2, 65001036500103.

WU, Y., CHIN, A., SHIH, K., WU, C., LIAO, C., PAI, S. \& CHI, C. 2000. Fabrication of very high resistivity Si with low loss and cross talk. Electron Device Letters, IEEE, 21, 442-444.

YUNAS, J., HAMZAH, A. A. \& MAJLIS, B. Y. 2009. Surface micromachined on-chip transformer fabricated on glass substrate. Microsystem Technologies, 15, 547552. 